\title{
Modeling acute kidney injury in kidney organoids with cisplatin
}

Jenny L. M. Digby ${ }^{l}$, Aneta Przepiorski $^{l}$, Alan J. Davidson ${ }^{1 *}$ and Veronika Sander ${ }^{l *}$

${ }^{1}$ Department of Molecular Medicine \& Pathology, University of Auckland, New Zealand

* These authors share senior authorship

Corresponding author: v.sander@auckland.ac.nz

\begin{abstract}
Acute kidney injury (AKI) remains a major global healthcare problem and there is a need to develop human-based models to study AKI in vitro. Towards this goal, we have characterized induced pluripotent stem cell-derived human kidney organoids and their response to cisplatin, a chemotherapeutic drug that induces AKI and preferentially damages the proximal tubule. We found that a single treatment with $50 \mu \mathrm{M}$ cisplatin induces HAVCRI and CXCL8 expression, DNA damage $(\gamma \mathrm{H} 2 \mathrm{AX})$ and cell death in the organoids in a dose-dependent manner but greatly impairs organoid viability. DNA damage was not specific to the proximal tubule but also affected the distal tubule and interstitial populations. This lack of specificity correlated with low expression of the proximal tubule-specific SLC22A2/OCT2 transporter for cisplatin. To improve viability, we developed a repeated low-dose regimen of $4 \mathrm{x} 5 \mu \mathrm{M}$ cisplatin over 7 days and found this causing less toxicity while still inducing a robust AKI response that included secretion of known AKI biomarkers and inflammatory cytokines. This work validates the use of human kidney organoids to model aspects of AKI in vitro, with the potential to identify new AKI biomarkers and develop better therapies.
\end{abstract}

Keywords: AKI, cisplatin, kidney organoids, repeated low-dose regimen, AKI biomarker, inflammation, cytokine, proximal tubule, nephrotoxicity 
bioRxiv preprint doi: https://doi.org/10.1101/2019.12.22.886572; this version posted December 23, 2019. The copyright holder for this preprint (which was not certified by peer review) is the author/funder. All rights reserved. No reuse allowed without permission.

\section{INTRODUCTION}

Acute kidney injury (AKI) is defined by the rapid decline of kidney function and is commonly caused by nephrotoxic side effects of clinical drugs. AKI is a serious condition that predisposes patients to chronic kidney disease (CKD) and mortality. However, there are no targeted therapies for AKI. This is partly due to a lack of clinically relevant models that are required to gain a better understanding of the pathological mechanisms involved in AKI and for the identification of early, reliable biomarkers to improve diagnostic accuracy of AKI $(15,19)$.

Cisplatin is a chemotherapeutic DNA cross-linking agent that is used to treat solid tumors. The anti-tumor efficacy of cisplatin is limited by severe nephrotoxicity, particularly affecting the $\mathrm{S} 3$ segment of the proximal tubule due to the high expression of drug transporters such as $S L C 22 A 2 / O C T 2$ (18). The renal pathology of cisplatin-induced AKI is multifactorial, consisting of inflammation, vascular injury, oxidative stress and direct toxicity via generation of reactive oxygen species (11).

In recent years, kidney organoids differentiated from human pluripotent stem cells (hPSC) have been established to study various types of kidney disorders $(5,8)$. Kidney organoids were reported to be susceptible to proximal tubule injury caused by nephrotoxins, such as cisplatin $(2,9,16,17)$. However, a full characterization of the effects of cisplatin in this system has been lacking.

We have developed a novel kidney organoid protocol that uses a simple, cost-effective method to generate large numbers of organoids, making it ideally suited for injury modeling and drug development (13). Here, we used these kidney organoids to analyze the effects and specificity of cisplatin-induced AKI. We found that cisplatin induces a dose-dependent upregulation of the proximal tubule injury marker HAVCRI and the inflammatory cytokine $C X C L 8$, DNA damage and cell death that compromised organoid viability. Cisplatin-induced DNA damage was not specific to the proximal tubule but found in the distal tubules and interstitial cells as well. An analysis of cisplatin transporter genes revealed that $S L C 22 A 2 / O C T 2$ was expressed at very low levels, providing a potential explanation for the lack of proximal tubule specificity. We found that repeated low doses of cisplatin improved organoid viability, while still inducing injury marker expression and secretion of AKI biomarkers and inflammatory cytokines.

\section{MATERIALS AND METHODS}

\section{iPSC maintenance and organoid generation}

All work was carried out with the approval of Human Participants Ethics Committees (UAHPEC 8712 and HDEC 17/NTA/204) and biosafety. iPSC maintenance and kidney organoid generation were performed as described (13). All experiments were performed using organoids generated from the MANZ-2 iPSC line (13).

\section{Cisplatin treatment}

Cisplatin was diluted from a $5 \mathrm{mM}$ stock in water. For the single high-dose regimen, a whole organoid assay of $\sim 500-800$ organoids was evenly split into 5 wells of a 6 -well ultra-low attachment plate (Corning). Cisplatin was added at $0,5,10,25$ or $50 \mu \mathrm{M}$ to 'stage II' medium (13) at day (d) 12 . Samples were collected $24 \mathrm{~h}$ and $48 \mathrm{~h}$ posttreatment, then analyzed using quantitative (q)PCR and immunohistochemistry. For the repeated low-dose regimen, $5 \mu \mathrm{M}$ cisplatin were added at $\mathrm{d} 12$ and subsequently every other day with the medium change for a total of 4 treatments over 7 days. Samples were collected on d19.

\section{RNA extraction, cDNA synthesis and qPCR}

Organoids were washed in PBS and homogenized in TRIzol. Total RNA was extracted using the GENEzol TriRNA Pure kit (Geneaid). RNA from fetal and adult kidney tissue was purchased from Takara. cDNA was synthesized using qScript cDNA SuperMix (Quanta). qPCR was performed using the PerfeCTa SYBR Green FastMix reagents (Quanta) on a QuantStudio 6 Flex Real-Time PCR machine. Gene expression was calculated using the $\mathrm{dCt}$ method using HPRT1 for normalization. Error bars represent standard deviation of triplicate measurements. All qPCR analyses were performed in organoids derived from two independent iPSC lines (MANZ-2 and RiPS or MANZ-4, (13).

\section{Histology and Immunohistochemistry}

Organoids were fixed in $4 \%$ paraformaldehyde/PBS. Paraffin embedding and sectioning was performed as described previously (13). Immunohistochemistry (IHC) was performed using standard procedures including heat-induced antigen retrieval. Hoechst 33342 was used for nuclear staining. Antibodies used were: $\gamma \mathrm{H} 2 \mathrm{AX}$ (Thermo Fisher CTE2577S and 14-9865-80), MAFB (Novus NBP1-81342), CDH1 (BD Biosciences 610181), 
bioRxiv preprint doi: https://doi.org/10.1101/2019.12.22.886572; this version posted December 23, 2019. The copyright holder for this preprint (which was not certified by peer review) is the author/funder. All rights reserved. No reuse allowed without permission.

MEIS1/2/3 (Active Motif 39796) and LTL (Vectorshield FL-1321). Cell death was measured by TUNEL assay using the ApopTag ${ }^{\circledR}$ Plus Fluorescein In Situ Detection kit (Millipore). Fluorescently stained sections were imaged on a Zeiss LSM710 confocal microscope.

\section{Quantification and statistics}

Quantification of IHC was performed on $\geq 10$ organoids per sample using ImageJ. For quantification of marker co-localization, double-positive cells were counted and normalized to the area of the respective tissue marker. Statistical significance was determined using one-way ANOVA or unpaired t-test in Prism (GraphPad). P-values $\leq 0.05$ were considered to be statistically significant. * p-value $\leq 0.05 ; * *$ p-value $\leq 0.01 ; * * *$ p-value $\leq 0.001$; $* * * * \mathrm{p}$-value $\leq 0.0001$.

\section{Cytokine array}

$\geq 20$ organoids per condition were cultured in a single well of a 24 -well ultra-low attachment plate in $500 \mu \mathrm{L}$ stage II medium \pm cisplatin for either $48 \mathrm{~h}$ (single dose cisplatin regimen) or for the last $48 \mathrm{~h}$ of the repeated low-dose regimen. Conditioned culture media were analyzed using the Proteome Profiler ${ }^{\mathrm{TM}}$ Human XL Cytokine Array (R\&D Systems). Signals were visualized with enhanced chemiluminescence on a Bio-Rad ChemiDoc ${ }^{\mathrm{TM}}$ MP Imaging system. Intensities of the duplicate signals were quantified using ImageJ. qPCR was performed to analyze changes in gene expression on RNA isolated from the same organoids as used for the cytokine array, as well as on organoids from independent assays (MANZ-2 and MANZ-4-derived).

\section{RESULTS}

Cisplatin induces AKI marker expression, DNA damage and cell death in kidney organoids

Previous studies reported cisplatin treatment of kidney organoids with doses ranging from 5-100 $\mu \mathrm{M}$ leading to induction of injury markers, apoptosis and DNA damage $(2,9,17)$. To investigate whether these findings were reproducible on kidney organoids generated with our protocol (13), we added single doses of 5, 10, 25 or $50 \mu \mathrm{M}$ of cisplatin to the culture medium of day (d) 12 organoids and collected samples 24 and 48 hours (h) post-treatment (Fig. 1A). Following the 24h treatment, expression of AKI marker HAVCRl (aka KIMl) remained unchanged after exposure to 5-25 $\mu \mathrm{M}$ cisplatin but increased 2.4-fold with $50 \mu \mathrm{M}$ cisplatin. After $48 \mathrm{~h}$, both 25 and $50 \mu \mathrm{M}$ cisplatin induced HAVCRI expression significantly (1.7 and 4.1-fold). A similar dose response was observed for expression of the inflammatory cytokine CXCL8. No significant change in expression was measured with 5-25 $\mu \mathrm{M}$ cisplatin, whereas $50 \mu \mathrm{M}$ cisplatin resulted in a 6.5- and 2.4-fold induction of CXCL8 $24 \mathrm{~h}$ and $48 \mathrm{~h}$ posttreatment, respectively (Fig. $1 \boldsymbol{B}$ ). To determine the extent of DNA damage and cell death as well as the spatial distribution of cells affected by cisplatin, we used $\gamma \mathrm{H} 2 \mathrm{AX}$ antibody and TUNEL staining on paraffin sections of control and cisplatin-treated organoids. Image analysis revealed that both markers were rare in the nuclei of control organoids but increased with 25 and $50 \mu \mathrm{M}$ of cisplatin (Fig. $1 C$ and $\boldsymbol{D}$ ). $\gamma \mathrm{H}_{2} \mathrm{AX}^{+}$and $\mathrm{TUNEL}^{+}$cells were scattered throughout the organoid sections with no obvious accumulation to tubules. These findings suggest that our kidney organoids respond to cisplatin treatment with induction of AKI markers as well as dose-dependent DNA damage and cell death, consistent with previous data $(9,17)$.

\section{Cisplatin targets interstitial cells}

We next investigated if our injury model could recapitulate the proximal tubule-specific cell damage found in AKI patients and animal models. Upon co-immunostaining of $\gamma \mathrm{H} 2 \mathrm{AX}$ with antibodies for podocytes, proximal tubule cells, distal tubule cells and interstitial cells, we observed that $\mathrm{MAFB}^{+}$podocytes were the least damaged by cisplatin (Fig. $2 A$ ). In contrast, $\gamma \mathrm{H} 2 \mathrm{AX}$ co-labeled a subset of $\mathrm{LTL}^{+}$proximal tubule cells, $\mathrm{CDH} 1^{+}$distal tubule cells and MEIS1/2/3+ interstitial cells in cisplatin-treated organoids (Fig. 2, B-D). Quantification revealed that 50 $\mu \mathrm{M}$ cisplatin induced a 5.5-fold increase in $\gamma \mathrm{H} 2 \mathrm{AX}^{+}$proximal tubule cells and a 3.7-fold increase in distal tubule cells compared to untreated controls (of $\mathrm{n} \geq 10$ organoids). Strikingly, the largest increase in $\gamma \mathrm{H} 2 \mathrm{AX}$ was found in interstitial cells (67-fold; Fig. $2 \boldsymbol{E}$ ). This result demonstrates that cisplatin predominantly targets the stromal compartment in kidney organoids. 
bioRxiv preprint doi: https://doi.org/10.1101/2019.12.22.886572; this version posted December 23, 2019. The copyright holder for this preprint (which was not certified by peer review) is the author/funder. All rights reserved. No reuse allowed without permission.

To elucidate why tubular cells were less susceptible to cisplatin-induced injury than interstitial cells, we measured the expression levels of cisplatin influx transporters encoded by $S L C 22 A 2 / O C T 2$, a major cisplatin transporter that is specifically expressed by proximal tubule cells, and SLC31A1/CTR1 and SLC31A2/CTR2 (4, 10). For cisplatin efflux we measured expression of $A T P 7 B$ and the SLC47A1/MATE1 and SLC47A2/MATE2K transporter genes, of which $S L C 47 A 2 / M A T E 2 K$ is uniquely expressed in the proximal tubule $(4,7)$. Three stages of organoid development (d8, d14 and d19) were analyzed alongside commercially available RNA of fetal and adult human kidneys using qPCR. We found that expression of SLC32A1/CTR1, SLC32A2/CTR2, ATP7B and SLC47A1/MATE1 increased with organoid maturation and was comparable to (or exceeded) the levels of these markers in fetal or adult kidney tissue. In contrast, expression of proximal tubule-specific SLC22A2/OCT2 and SLC47A2/MATE2K transporters was equally low in organoids and fetal kidney (Fig. 2 F).

\section{Repeated low-dose cisplatin treatment reduces cytotoxicity}

As shown above, exposure of organoids to 25 and $50 \mu \mathrm{M}$ cisplatin for $48 \mathrm{~h}$ leads to acute DNA damage and cell death (Fig. $1 C$ and $\boldsymbol{D}$ ). At collection on d14, the cisplatin-treated organoids appeared healthy and similar in morphology to untreated controls (not shown). However, treated organoids deteriorated at later stages of culture whereas untreated controls retained a healthy appearance (Fig. 3A). To increase organoid viability and to more closely mimic the repeated dosing regimen of chemotherapy, we tested a repeated low-dose cisplatin regimen on the organoids. To do this, $5 \mu \mathrm{M}$ cisplatin was added at days $12,14,16$ and $18(4 \mathrm{x} 5 \mu \mathrm{M})$ before collection at d19 (Fig. 3B). qPCR revealed a 5.5-fold induction of HAVCRl and 19-fold induction of $C X C L 8$ in $4 \times 5 \mu \mathrm{M}$ cisplatintreated organoids compared to controls (Fig. 3C). Importantly, no tissue disintegration was observed at later stages, indicative of improved organoid viability (Fig. $3 D$ ).

An analysis of $4 \mathrm{x} 5 \mu \mathrm{M}$-treated organoids for $\gamma \mathrm{H} 2 \mathrm{AX}$ and TUNEL by IHC showed that both markers increased to a similar extent as with the single treatment (2.7- and 3.6-fold, respectively; Fig. 3, $\boldsymbol{D}$ and $\boldsymbol{E}$ ). Co-labeling of $\gamma \mathrm{H} 2 \mathrm{AX}^{+}$nuclei with the tissue markers MAFB, LTL, CDH1, MEIS1/2/3 (Fig. 4, $\boldsymbol{A}-\boldsymbol{D}$ ) showed that cisplatin had the greatest effect on interstitial cells (20-fold), whereas for the tubular compartment there was a trend for more proximal tubule injury (3.1-fold) relative to the distal (1.7-fold; Fig. 4, E). Taken together, the repeated low-dose cisplatin treatment recapitulated the induction of kidney injury marker expression observed upon exposure to single high-dose cisplatin, yet exhibited less DNA damage in interstitial cells and improved organoid viability.

\section{$4 \times 5 \mu M$ cisplatin-treated organoids secrete inflammatory cytokines and AKI biomarkers}

Having improved the injury regimen, we next surveyed the cytokines secreted into the medium in response to cisplatin using the Proteome Profiler Human XL Cytokine Array, a membrane-based sandwich immunoassay that can detect 102 cytokines. We found 12 secreted factors with a $\geq 2$-fold increase in signal intensity upon cisplatin treatment (SERPINE1/PAI-1, CXCL1, CXCL5, PDGFA, CXCL8, PTX3, CCL7, VCAM1, CCL20, CXCL10, IL17A and MMP9 (Fig. $\mathbf{4 F}$, green boxes)), and decreased secretion of the Wnt-inhibitor DKK1 (Fig. $\mathbf{4 F}$, red box). qPCR analysis of the genes encoding these factors revealed that differential protein secretion correlated to changes in gene expression (Fig. 4G). As several of these cytokines have been implicated in acute or chronic kidney injury (CXCL1, CXCL5, CCL7, CCL20, IL17A) and renal fibrosis (SERPINE1, PDGFA, MMP9), these data demonstrate the utility of cisplatin-treated kidney organoids as a platform to identify AKI biomarkers and cytokines that model the inflammatory profile seen in AKI (6).

\section{DISCUSSION}

The main finding of this work is that cisplatin, both the single high-dose and repeated low-dose regimen, damages all cellular compartments in the organoids but has the most profound effect on interstitial cells. This is in contrast to previous reports, where a single dose of $5 \mu \mathrm{M}$ cisplatin was suggested to cause DNA damage and apoptosis specifically to proximal tubules $(9,17)$. Given the low expression of SLC22A2/OCT2 in our kidney organoids, we speculate that cisplatin uptake occurs via the widely-expressed CTR transporters and thus, accounts for the lack of proximal-tubule specific damage (12). As SLC22A2/OCT2 is not normally expressed in the fetal human kidney, and as kidney organoids represent a fetal stage of differentiation $(13,17)$, the lack of SLC22A2/OCT2 expression is most likely due to immaturity of our organoids. This lack of specificity may not apply to kidney organoids generated by other protocols that can be cultured for longer periods. The high rate of stromal cell proliferation, as compared to the tubular cells, may be responsible for the enriched susceptibility to DNA damage we observe in 
bioRxiv preprint doi: https://doi.org/10.1101/2019.12.22.886572; this version posted December 23, 2019. The copyright holder for this preprint (which was not certified by peer review) is the author/funder. All rights reserved. No reuse allowed without permission.

these cells, given that cisplatin targets dividing cells (18). Together, our findings suggest that cisplatin exerts a general cytotoxic effect on kidney organoids reminiscent of the impact of the drug on tumor cells, rather than acting as a specific proximal tubule nephrotoxin.

We found that there was a trend for more DNA damage in the proximal tubule over the distal tubule when cisplatin was administered with the repeated low-dose regimen. As this is unlikely due to tubule maturation, we speculate that the $4 \mathrm{x} 5 \mu \mathrm{M}$ regimen avoids the acute cell death response of the $50 \mu \mathrm{M}$ dose, and instead leads to a milder yet accumulative injury phenotype that manifests in robust activation of known AKI markers and cytokines associated with AKI. Such a scenario is more representative of chemotherapeutic low-dose cisplatin administered over an extended period of time, whereby sustained inflammation is a contributing factor to the transition from AKI to renal fibrosis and CKD (14). Our 4 x $5 \mu \mathrm{M}$ approach is also consistent with recent work in mice, where repeated low-dose cisplatin regimens were shown to induce inflammatory cytokines and fibrosis markers in contrast to the acute toxicity, high mortality and lack of fibrosis seen with a single high-dose treatment $(1,3,15)$.

Lastly, we show that the proteome array allows for detection of proteins secreted in response to a nephrotoxic insult, analogous to measuring serum and urine markers in AKI patients. This assay provides a proof-of-principle for more sensitive detection tools, such as ELISA, to be used to identify new AKI biomarkers and perform drugscreening approaches. In summary, our organoid model of cisplatin-induced AKI shows limited specificity of injury but a strong representation of the inflammatory response to nephrotoxic insults, and thus provides a valuable system for drug and biomarker discovery that are urgently needed to improve the treatment of patients with AKI.

\section{ACKNOWLEDGEMENTS}

We thank G. Chang for critical reading of the manuscript.

Present address of A. Przepiorski: Department of Developmental Biology, University of Pittsburgh, Pittsburgh, PA, USA

\section{GRANTS}

This work was supported by the Health Research Council of New Zealand (17/425).

\section{DISCLOSURES}

No conflicts of interest, financial or otherwise, are declared by the authors.

\section{AUTHOR CONTRIBUTIONS}

V.S. and A.J.D. conceptualized the study, J.D., A.P. and V.S. performed experiments, J.D. and V.S. analyzed the data, V.S. and A.J.D. wrote the manuscript, V.S. and A.J.D. supervised the study, and A.J.D. acquired funding.

\section{REFERENCES}

1. Black L, Lever JM, Traylor AM, Chen B, Yang Z, Esman S, Jiang Y, Cutter G, Boddu R, George J, Agarwal A. Divergent effects of AKI to CKD models on inflammation and fibrosis. Am J Physiol-renal 2018. doi: 10.1152/ajprenal.00179.2018.

\section{Freedman BS, Brooks CR, Lam AQ, Fu H, Morizane R, Agrawal V, Saad AF, Li MK, Hughes MR, Werff R, Peters DT, Lu J, Baccei A, Siedlecki AM, Valerius TM, Musunuru K, McNagny KM, Steinman TI, Zhou J, Lerou PH, Bonventre JV. Modelling kidney disease with CRISPR-mutant kidney organoids derived from human pluripotent epiblast spheroids. Nature Communications 6: ncomms9715, 2015.}

3. Fu Y, Cai J, Li F, Liu Z, Shu S, Wang Y, Liu Y, Tang C, Dong Z. Chronic effects of repeated low dose cisplatin treatment in mouse kidneys and renal tubular cells. Am J Physiol-renal 2019. doi: 10.1152/ajprenal.00385.2019.

4. Harrach S, Ciarimboli G. Role of transporters in the distribution of platinum-based drugs. Frontiers in Pharmacology 6: 85, 2015. 
bioRxiv preprint doi: https://doi.org/10.1101/2019.12.22.886572; this version posted December 23, 2019. The copyright holder for this preprint (which was not certified by peer review) is the author/funder. All rights reserved. No reuse allowed without permission.

5. Little MH, Combes AN. Kidney organoids: accurate models or fortunate accidents. Gene Dev 33: 1319$1345,2019$.

6. Liu J, Kumar S, Dolzhenko E, Alvarado GF, Guo J, Lu C, Chen Y, Li M, Dessing MC, Parvez RK, Cippà PE, Krautzberger MA, Saribekyan G, Smith AD, McMahon AP. Molecular characterization of the transition from acute to chronic kidney injury following ischemia/reperfusion. Jci Insight 2: e94716, 2017.

7. Masuda S, Terada T, Yonezawa A, Tanihara Y, Kishimoto K, Katsura T, Ogawa O, Inui K. Identification and Functional Characterization of a New Human Kidney-Specific H+/Organic Cation Antiporter, Kidney-Specific Multidrug and Toxin Extrusion 2. J Am Soc Nephrol 17: 2127-2135, 2006.

8. Miyoshi T, Hiratsuka K, Saiz E, Morizane R. Kidney organoids in translational medicine: Disease modeling and regenerative medicine. Dev Dynam 2019. doi: 10.1002/dvdy.22.

9. Morizane R, Lam AQ, Freedman BS, Kishi S, Valerius TM, Bonventre JV. Nephron organoids derived from human pluripotent stem cells model kidney development and injury. Nature Biotechnology 33: 1193-1200, 2015 .

10. Otsuka M, Matsumoto T, Morimoto R, Arioka S, Omote H, Moriyama Y. A human transporter protein that mediates the final excretion step for toxic organic cations. Proc National Acad Sci 102: 17923-17928, 2005 .

11. Ozkok A, Edelstein CL. Pathophysiology of Cisplatin-Induced Acute Kidney Injury. BioMed Research International 2014: 1-17, 2014.

12. Pabla N, Murphy RF, Liu K, Dong Z. The copper transporter Ctr1 contributes to cisplatin uptake by renal tubular cells during cisplatin nephrotoxicity. Am J Physiol-renal 296: F505-F511, 2009.

13. Przepiorski A, Sander V, Tran T, Hollywood JA, Sorrenson B, Shih J-H, Wolvetang EJ, McMahon AP, Holm TM, Davidson AJ. A Simple Bioreactor-Based Method to Generate Kidney Organoids from Pluripotent Stem Cells. Stem Cell Reports, 2018.

14. Sato Y, Yanagita M. Immune cells and inflammation in AKI to CKD progression. Am J Physiol-renal 315: F1501-F1512, 2018.

15. Sharp CN, Siskind LJ. Developing Better Mouse Models to Study Cisplatin-Induced Kidney Injury. Am J Physiol-renal 313: F835-F841, 2017.

16. Soo J, Jansen J, Masereeuw R, Little MH. Advances in predictive in vitro models of drug-induced nephrotoxicity. Nat Rev Nephrol 14: 378-393, 2018.

17. Takasato M, Er PX, Chiu HS, Maier B, Baillie GJ, Ferguson C, Parton RG, Wolvetang EJ, Roost MS, de Lopes SM, Little MH. Kidney organoids from human iPS cells contain multiple lineages and model human nephrogenesis. Nature 526: nature15695, 2015.

18. Yao X, Panichpisal K, Kurtzman N, Nugent K. Cisplatin Nephrotoxicity: A Review. Am J Med Sci 2: 115-124, 2007.

19. Zuk A, Bonventre JV. Acute Kidney Injury. Annual Review of Medicine 67: 293-307, 2016.

\section{FIGURE LEGENDS}

Fig. 1. Cisplatin induces tubular injury, DNA damage and cell death in kidney organoids. $A$ : Schematic of cisplatin treatment on kidney organoids. B: qPCR showing elevated expression of HAVCRI and CXCL8 with increasing doses of cisplatin. $C$ and $D$ : IHC stainings on paraffin sections of d 14 organoids and quantification showing DNA damage marker $\gamma \mathrm{H} 2 \mathrm{AX}$ and cell death marker TUNEL increased with 25 and $50 \mu \mathrm{M}$ cisplatin. n.s., not significant. Scale bars, $100 \mu \mathrm{m}$. 
Fig. 2. Cisplatin predominantly targets interstitial cells in kidney organoids. $A-D$ : IHC staining for co-localization of DNA damage marker $\gamma \mathrm{H} 2 \mathrm{AX}$ with $\mathrm{MAFB}^{+}$podocytes, $\mathrm{LTL}^{+}$proximal tubules, $\mathrm{CDH}^{+}$distal tubules and MEIS1/2/3 $3^{+}$interstitial cells in control and $50 \mu \mathrm{M}$ cisplatin-treated organoids. $E$ : Ratio of $\gamma \mathrm{H} 2 \mathrm{AX}^{+}$cells per marker. $F$ : qPCR showing expression of cisplatin transporters in d8, d14 and d19 kidney organoids, and fetal and adult human kidneys. Scale bars, $100 \mu \mathrm{m}$.

Fig. 3. Repeated exposure to low-dose cisplatin reduces cell death and structural deterioration. A: Brightfield imaging showing healthy organoids at $\mathrm{d} 19$ and organoid deterioration after $50 \mu \mathrm{M}$ cisplatin. $B$ : Schematic of repeated low-dose cisplatin treatment. $C$ : qPCR analysis of d19 organoids showing HAVCRl and CXCL8 expression increased upon $4 \times 5 \mu \mathrm{M}$ cisplatin. $D$ : Organoids treated with $4 \times 5 \mu \mathrm{M}$ cisplatin maintain tubular structures. $E$ and $F$ : IHC showing DNA damage marker $\gamma \mathrm{H} 2 \mathrm{AX}$ and cell death marker TUNEL increased with $4 \mathrm{x}$ $5 \mu \mathrm{M}$ cisplatin. Scale bars, $400 \mu \mathrm{m}$.

Fig. 4. Organoids secrete AKI biomarkers and cytokines in response to cisplatin. $A-D$ : IHC on d19 control and $4 \mathrm{x}$ $5 \mu \mathrm{M}$ cisplatin-treated organoids for co-localization of DNA damage $(\gamma \mathrm{H} 2 \mathrm{AX})$ with kidney tissues $\left(\mathrm{MAFB}^{+}\right.$ podocytes, $\mathrm{LTL}^{+}$proximal tubules, $\mathrm{CDH}^{+}$distal tubules, MEIS1/2/3+ interstitial cells). E: Quantification of $\gamma \mathrm{H} 2 \mathrm{AX}$ co-localization with kidney tissues. $F$ : Cytokine array analysis using culture media collected from control and 4 x $5 \mu \mathrm{M}$ cisplatin-treated organoids. Factors with higher (green boxes) or lower (red box) secretion in cisplatin-treated versus control organoids are indicated. $G$ : qPCR showing transcriptional changes of the cytokines. Expression of IL17A was below the detection limit. Scale bars, $100 \mu \mathrm{m}$. 


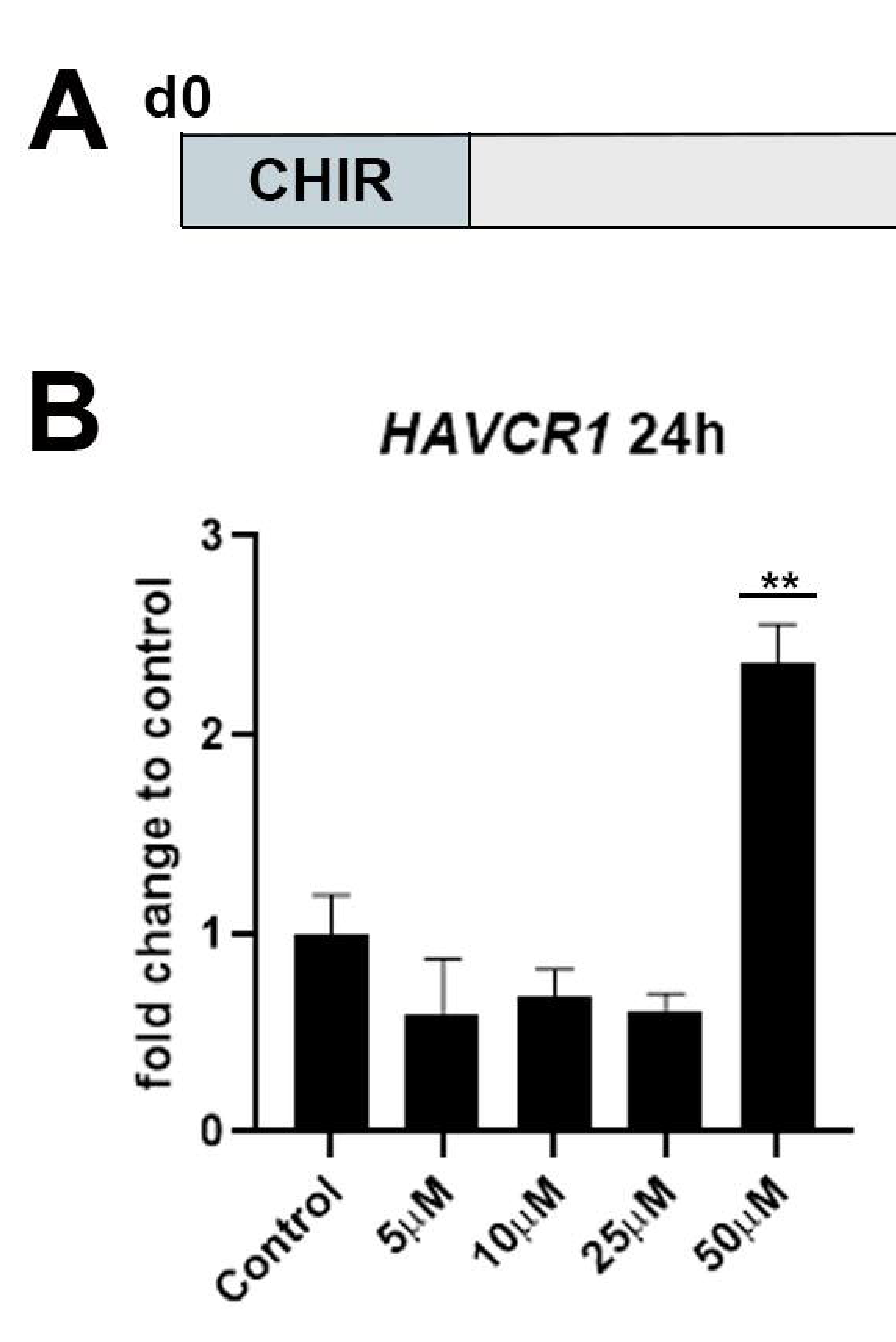

d12 + cisplatin $(5-50 \mu \mathrm{M})$

* Analysis on d13, d14

B
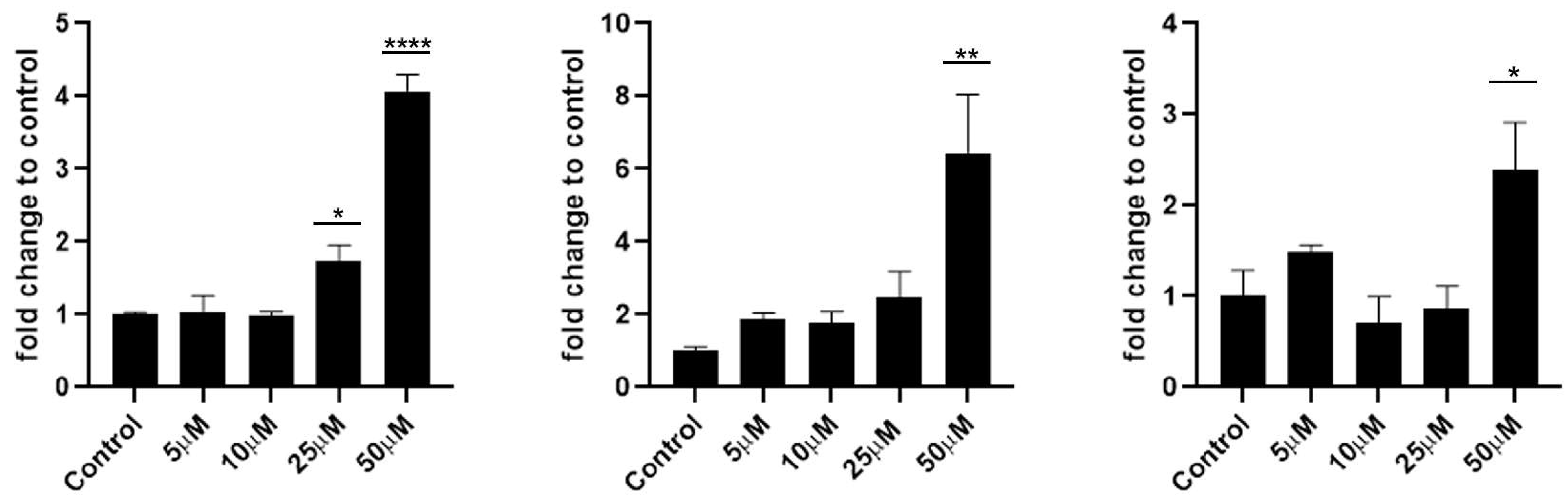

Control, d14

$+25 \mu \mathrm{M}$ cisplatin, 48h
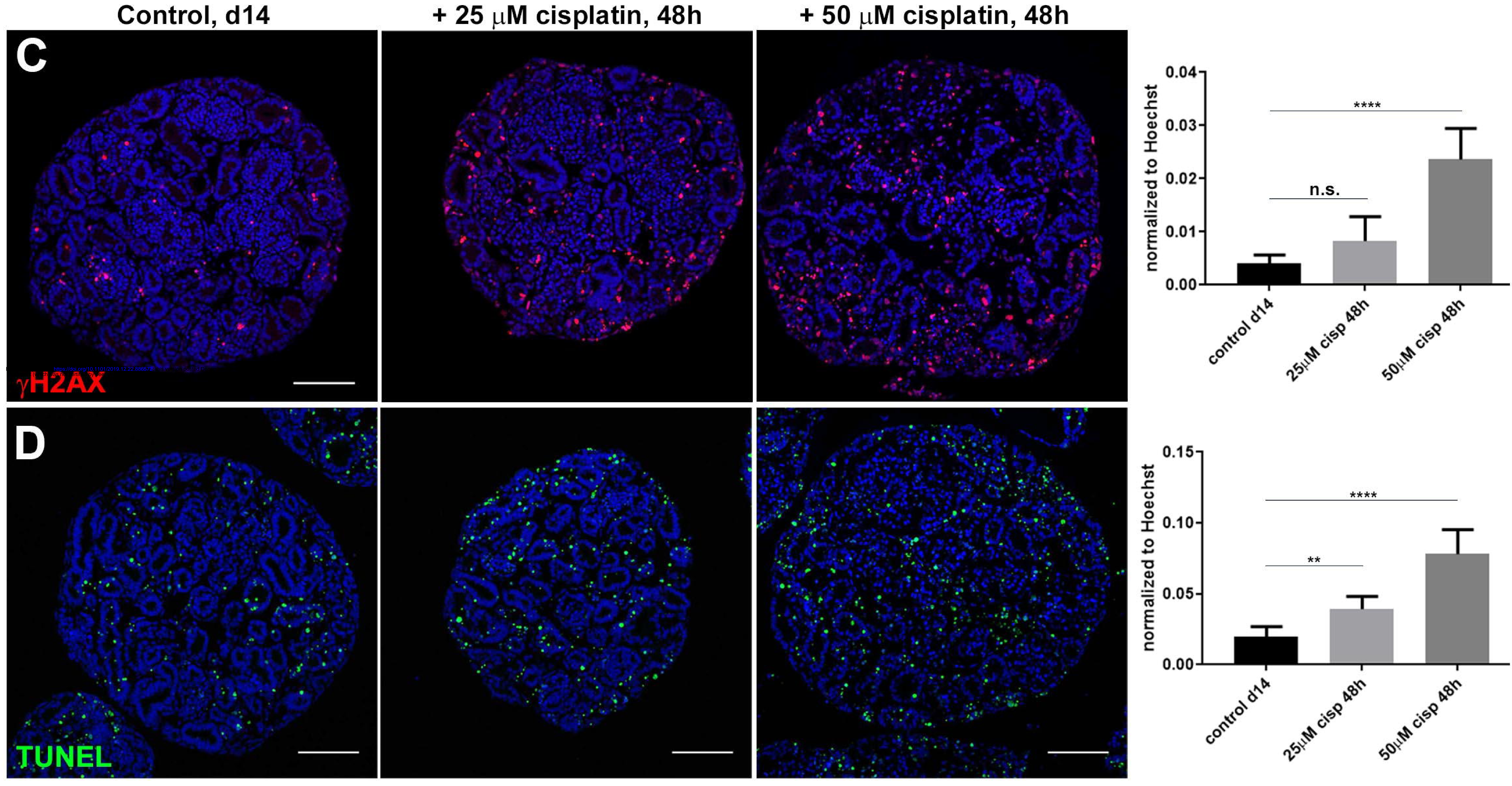


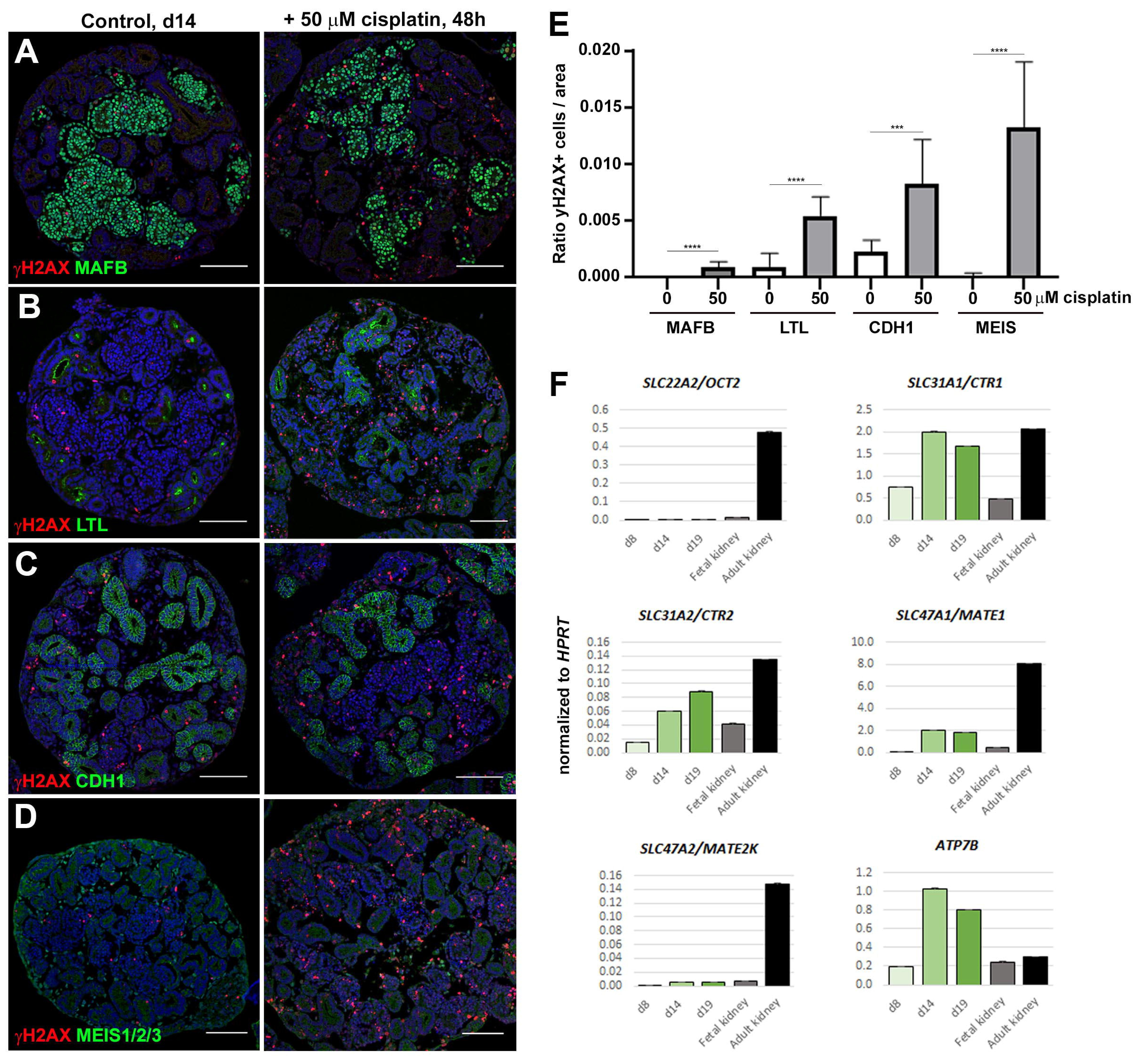


A Control, d19

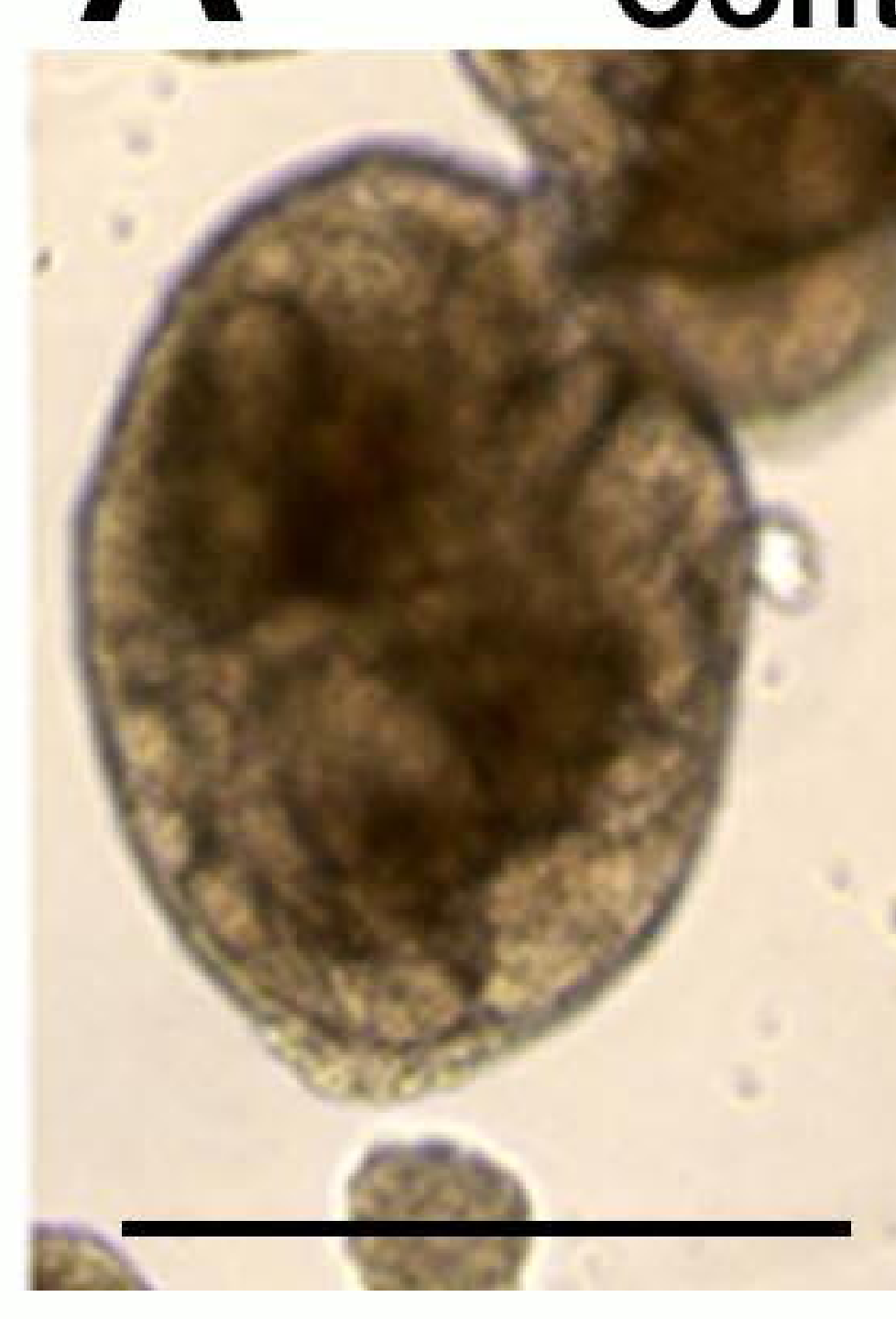

C

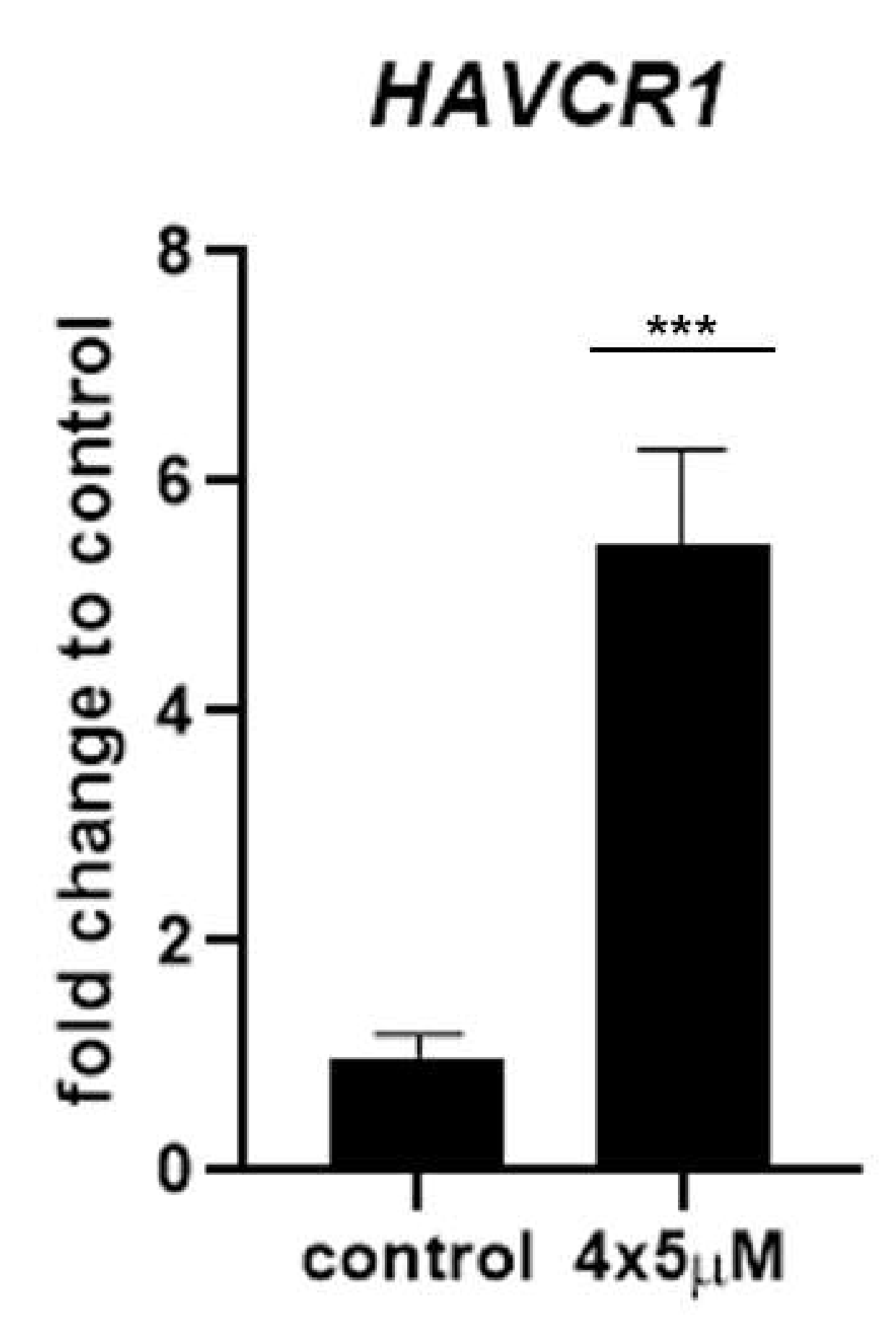

Control, d19

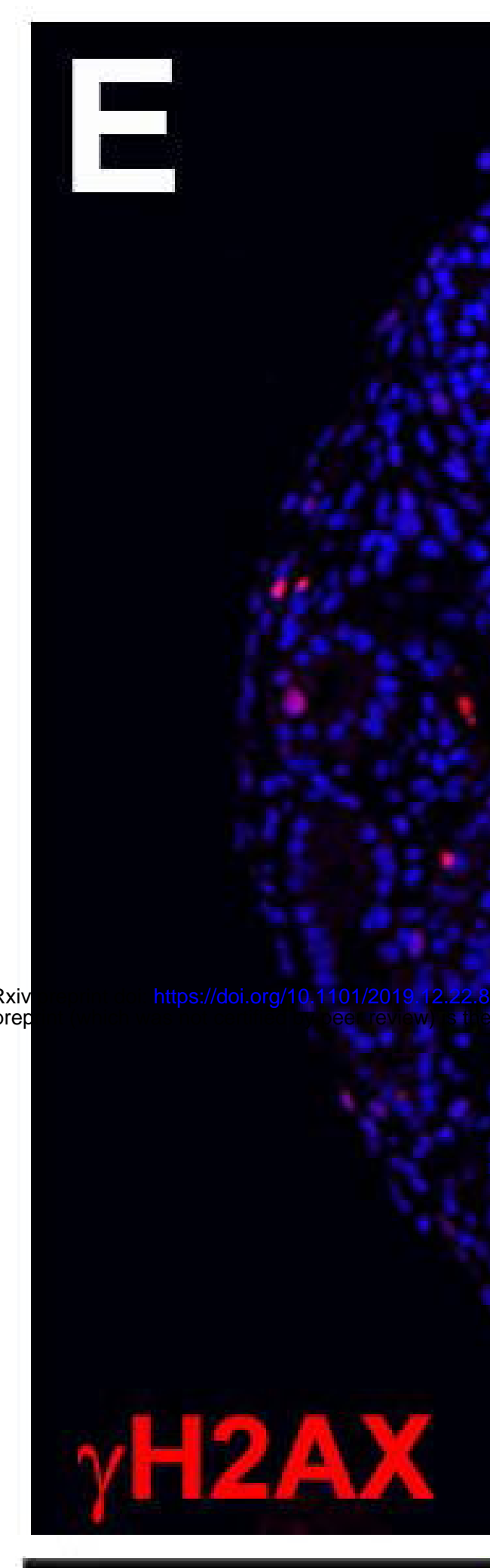

Control. dig

$F$

TUNEL

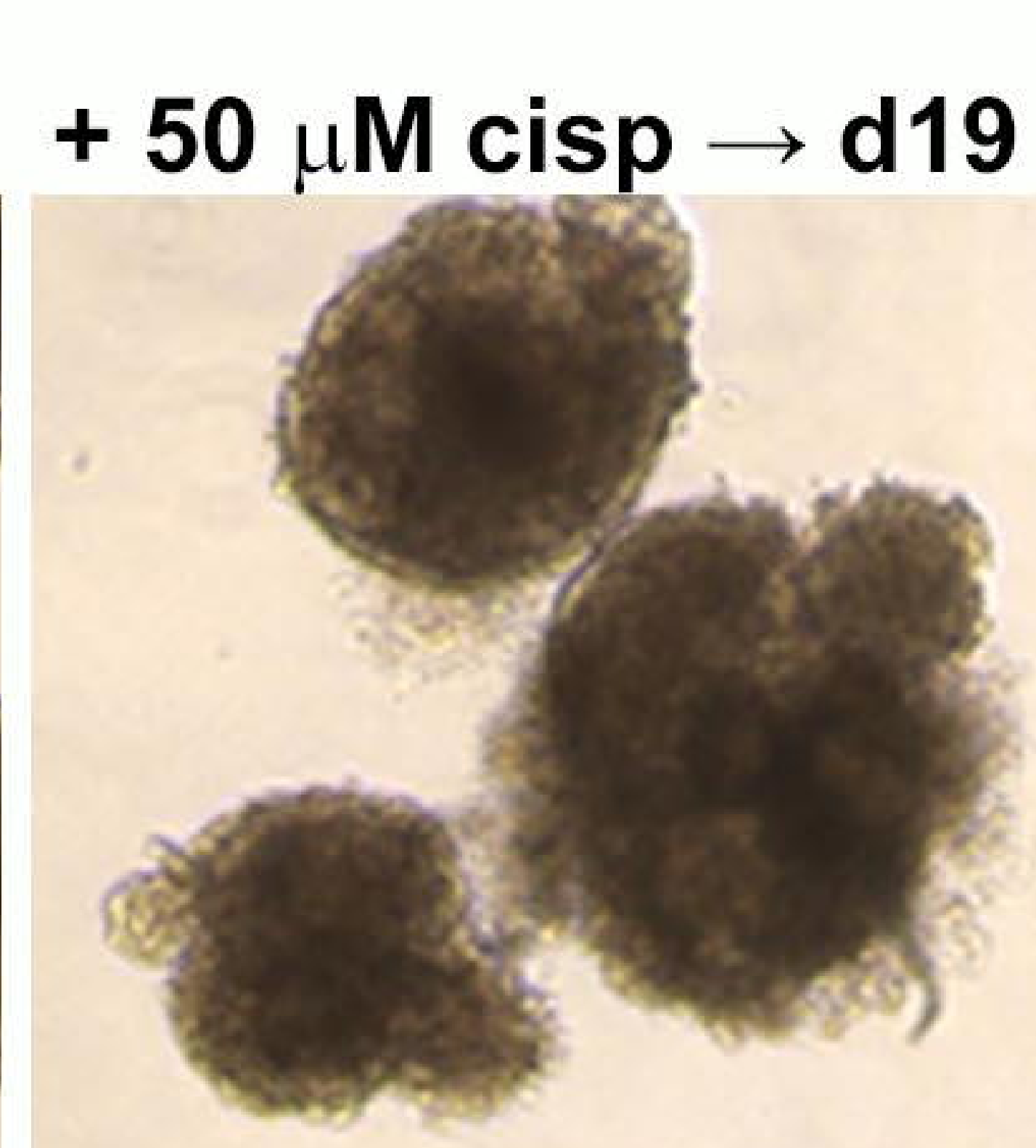

B

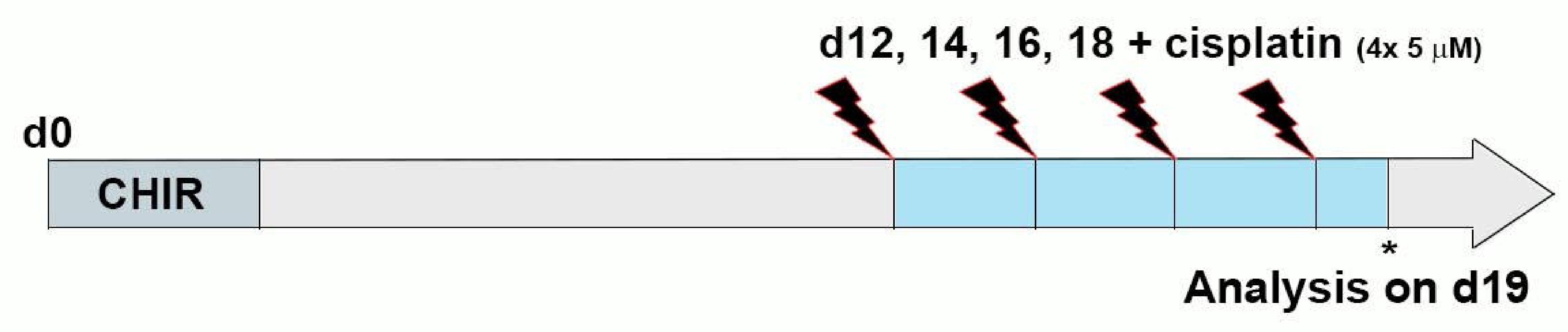

D
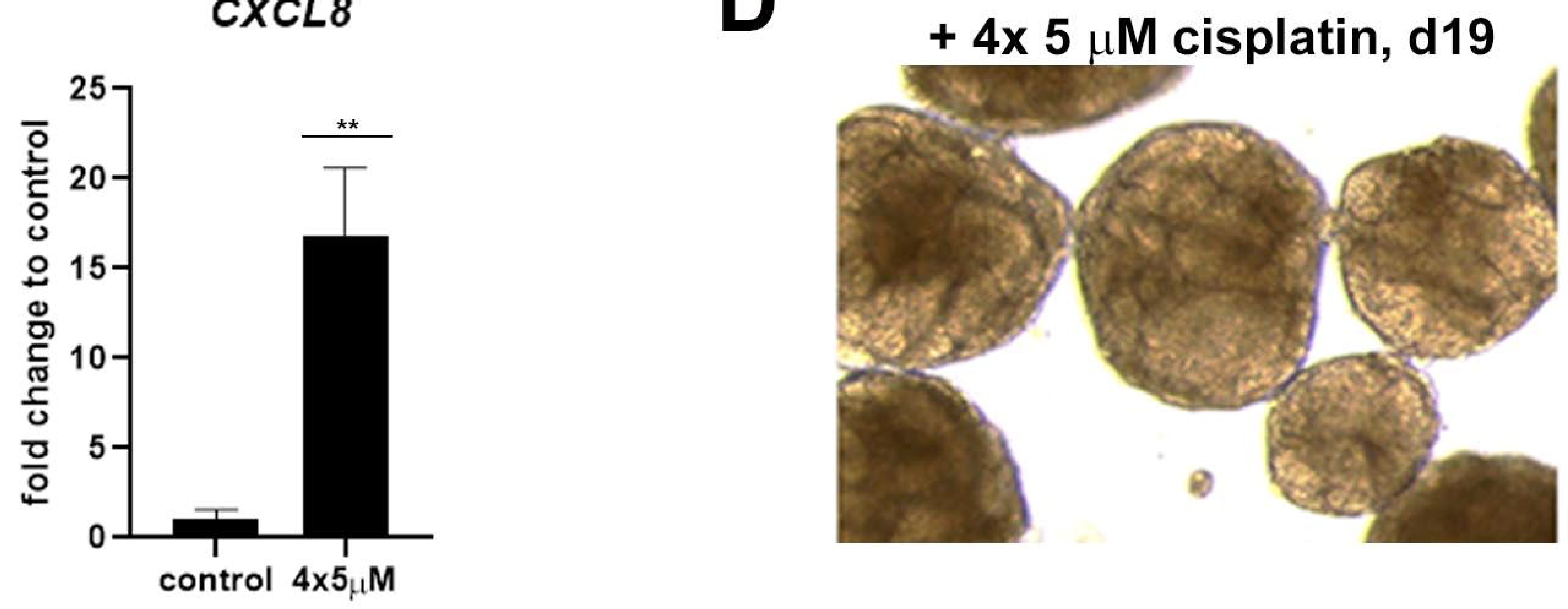

+ 4x $5 \mu \mathrm{M}$ cisplatin

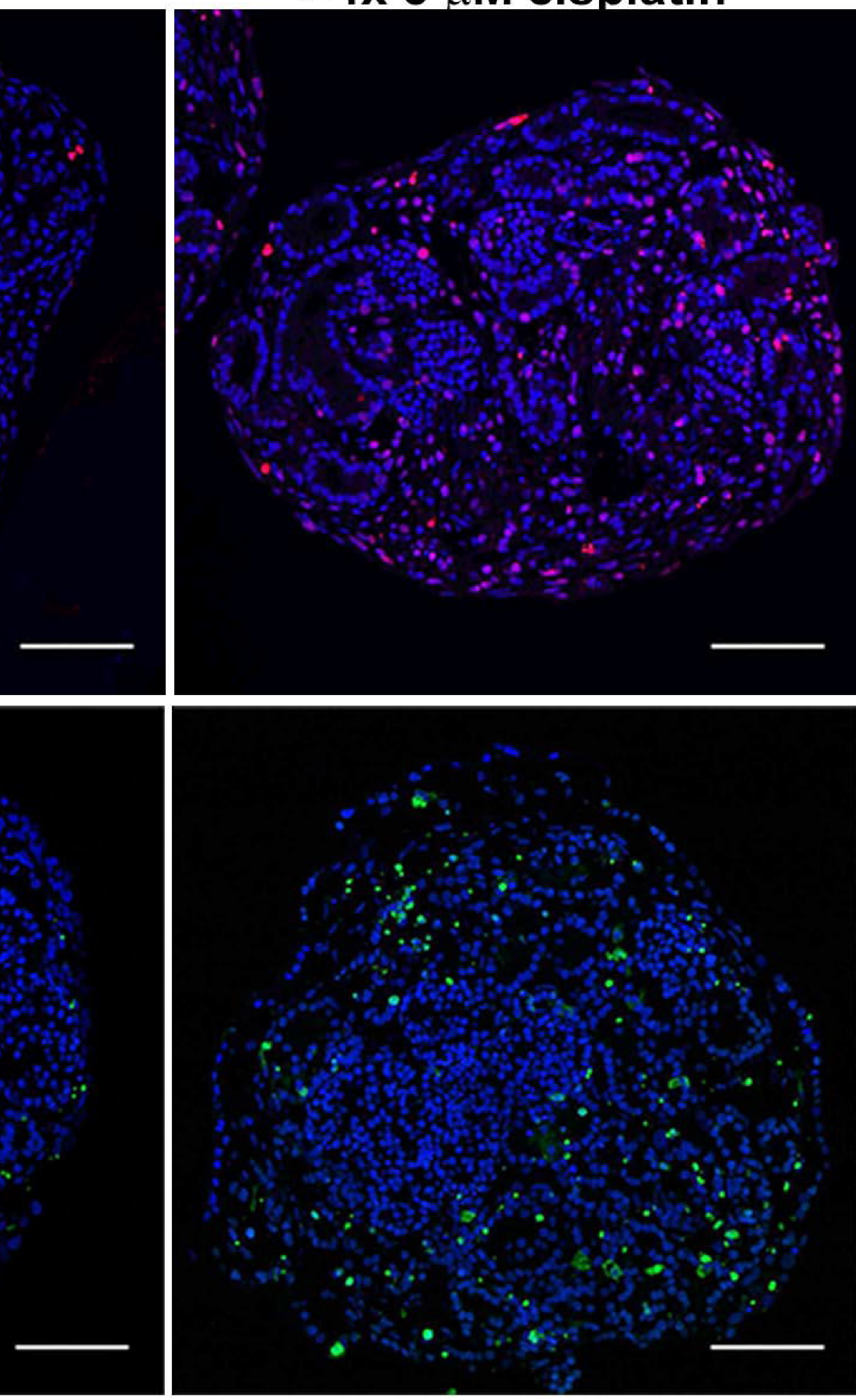

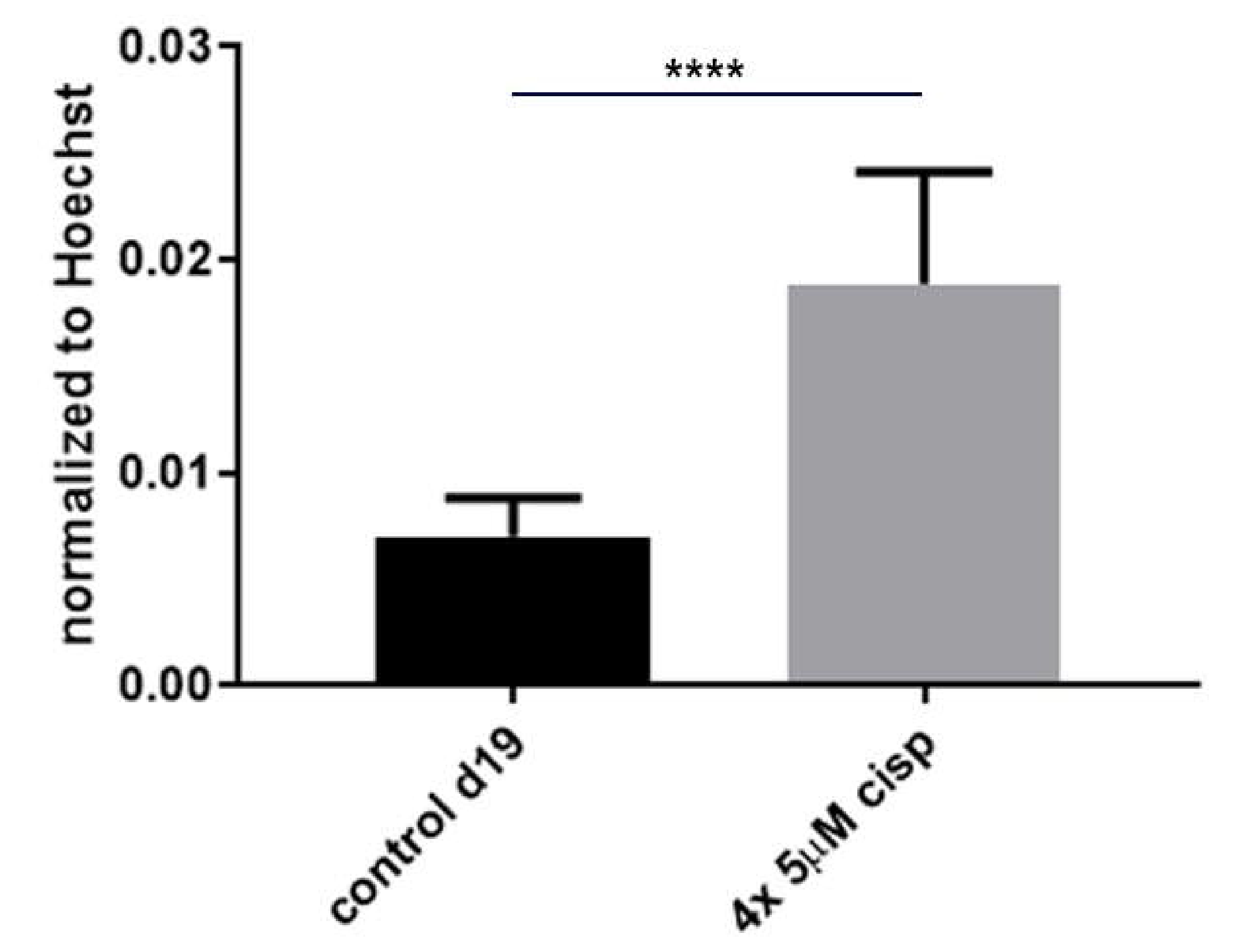

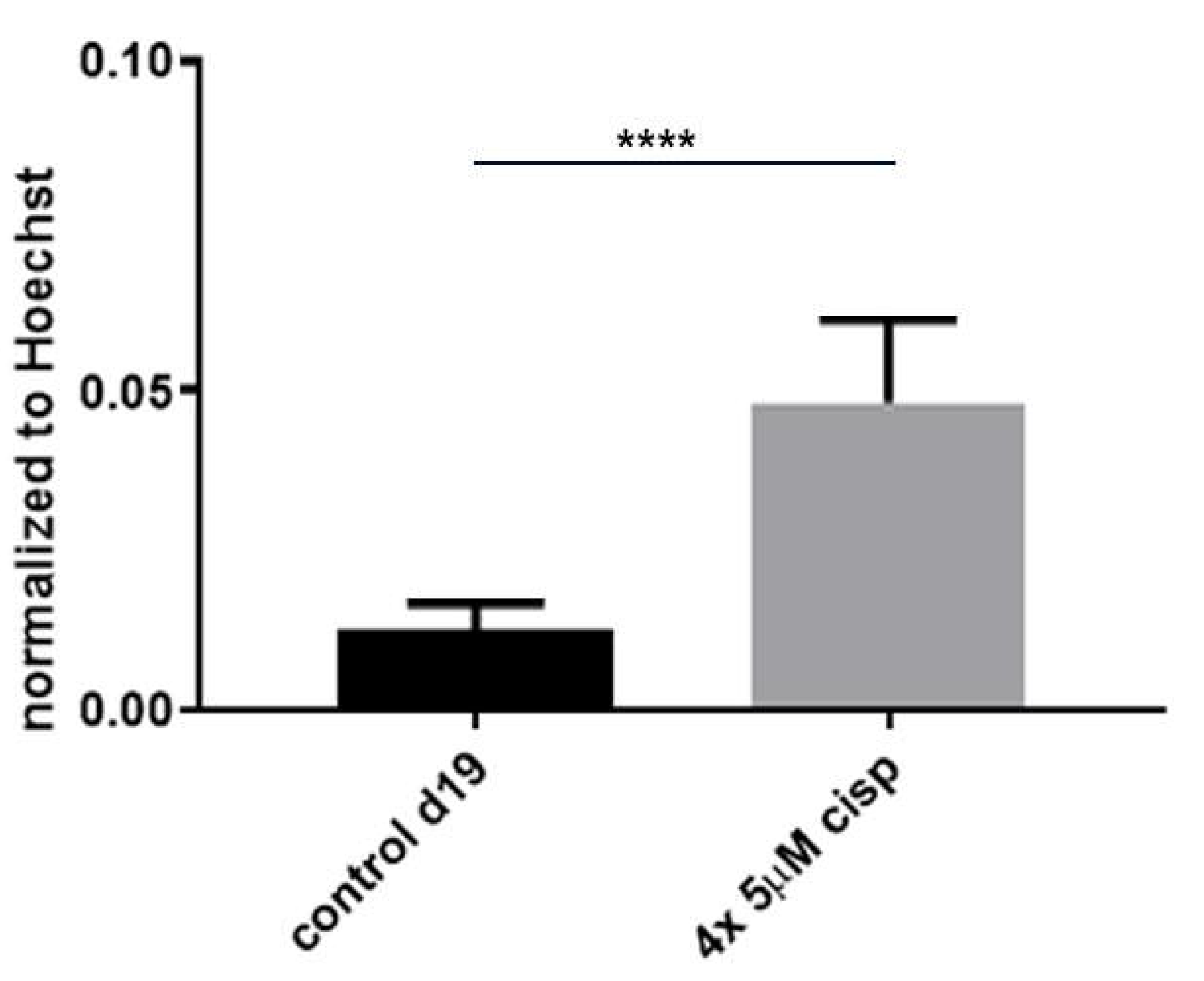




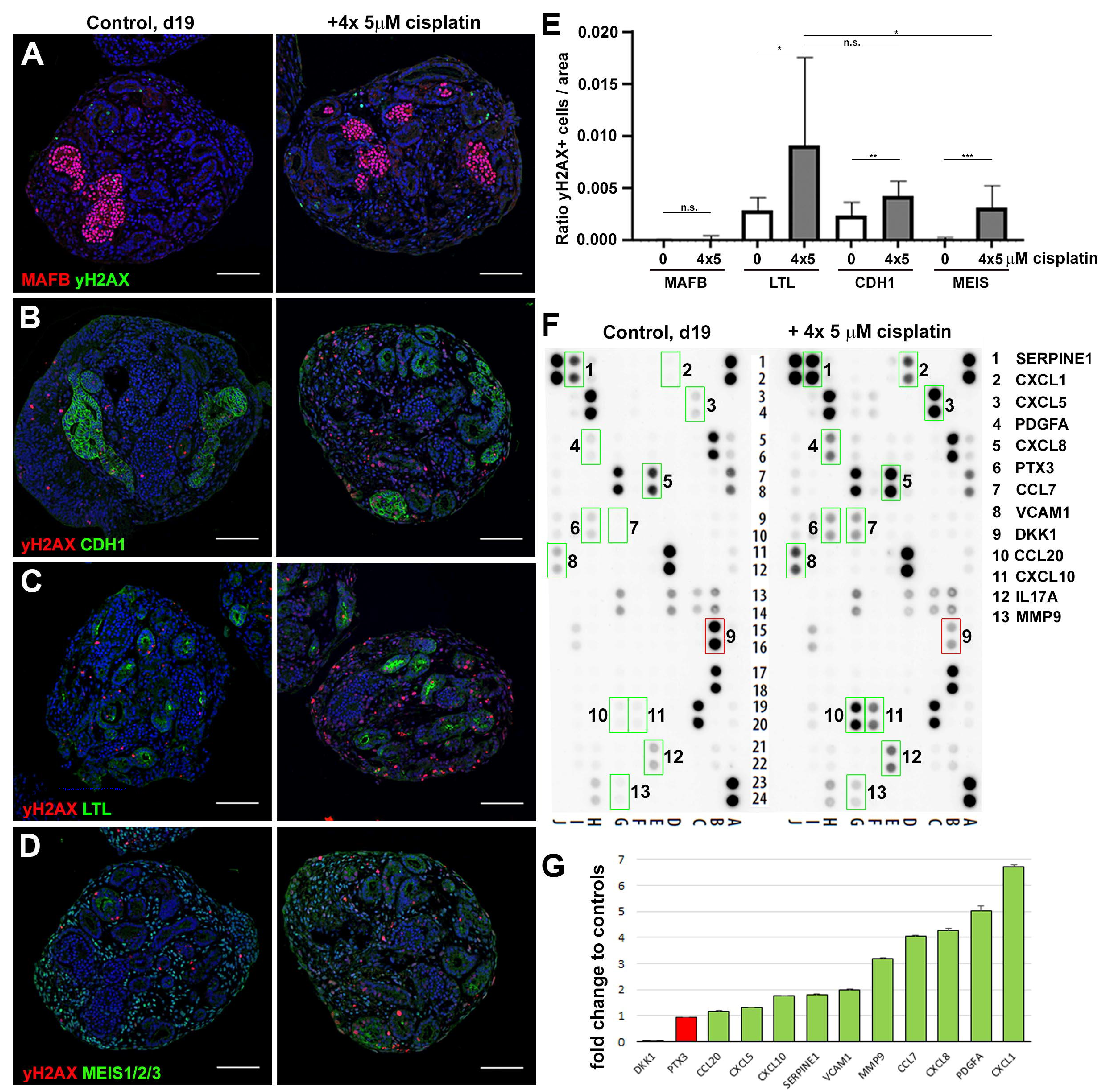

